\title{
Bilateral Single System Ectopic Ureters With Ureterocele: A Rare Association in an Adult Male
}

\author{
Harjinder Singha, ${ }^{\mathrm{a}, \mathrm{c}}$, Anand Singla ${ }^{\mathrm{b}}$, Anahat Kaur ${ }^{\mathrm{b}}$
}

\begin{abstract}
Bilateral single system ectopic ureter (BSSEU) is a rare congenital malformation. We report a case of BSSEU with a rare association of ectopic ureter with contralateral ectopic sphinctero-stenotic ureterocele with agenesis of one seminal vesicle with normal urinary continence and fertility presenting in adulthood as a case of chronic kidney disease. Diagnosis of ureterocele was missed even after detailed radiological investigations, so concurrent endoscopic evaluation is important for final diagnosis and operative intervention. As renal functions were markedly deranged, so transurethral incision of the right ureterocele with double $\mathrm{J}$ stenting was done as a preliminary procedure. Renal functions improved subsequently. Patient is planned for left nephroureterectomy and if necessary right ureteric reimplantation as a secondary major surgery in the follow-up period.
\end{abstract}

Keywords: Bilateral single system; Ectopic ureters; Prostatic urethra; Ectopic ureterocele

\section{Introduction}

Bilateral single system ectopia is a rare congenital anomaly. A ureter that opens at a site other than the posterolateral aspect of the trigone is known as ectopic ureter [1]. The bilateral single system ureteral ectopia arises from the cranial origin of the ureteric buds from the mesonephric ducts resulting in delay in their incorporation into the urogenital sinus. This limits the ingrowth of mesenchyme necessary for the forma-

Manuscript accepted for publication May 8, 2014

${ }^{a}$ Department of Urology, Government Medical College, Patiala, Punjab 147001, India

${ }^{\mathrm{b}}$ Government Medical College, Patiala, Punjab 147001, India

${ }^{\mathrm{c} C}$ Corresponding Author: Harjinder Singh, Department of Urology,

Government Medical College, Patiala, Punjab, India.

Email: dr.hsingh.uro@gmail.com

doi: http://dx.doi.org/10.14740/wjnu162w tion of the trigone and the vesical neck because of which an absent trigone or a poorly developed bladder neck is invariably seen in patients with bilateral single system ureteral ectopia [2].

In males the ectopic ureters always enter the urogenital system above the external sphincter and usually into the Wolffian structures including the vas deferens, seminal vesicles or ejaculatory duct. Males do not present with incontinence but with infection and pain of the affected organs [3]. In females urinary incontinence is seen frequently in bilateral single system ectopic ureters (BSSEUs) due to the absence of bladder neck and trigone. BSSEU may be associated with a hypoplastic bladder and bilateral renal abnormalities. Some of the children may be considered to have bladder agenesis due to the absence of a recognizable bladder structure. The possibility of bladder developing normal size and function stays uncertain posing a major surgical challenge to the urologists. We present a case of BSSEU opening into prostatic urethra with a rare association of ectopic ureter with contralateral ureterocele with agenesis of left seminal vesicle in an adult male having normal bladder functions and fertility.

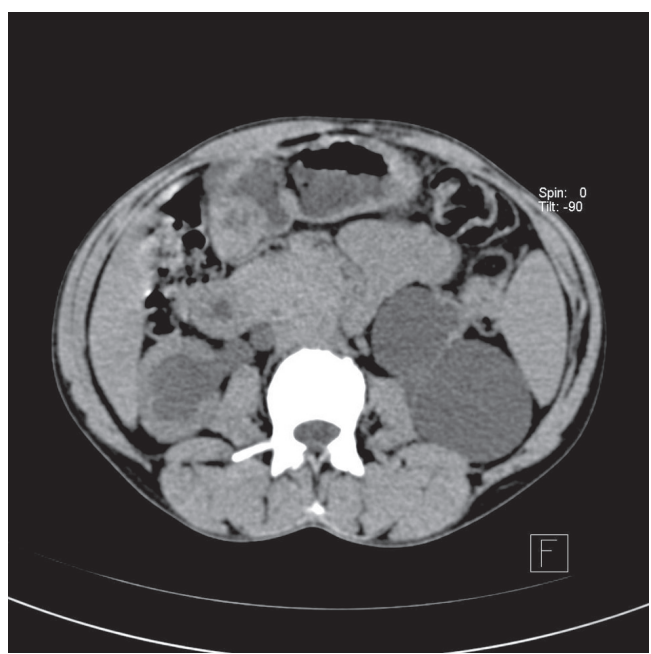

Figure 1. CT abdomen showing bilateral hydronephrosis with hardly any parenchyma on the left side. 


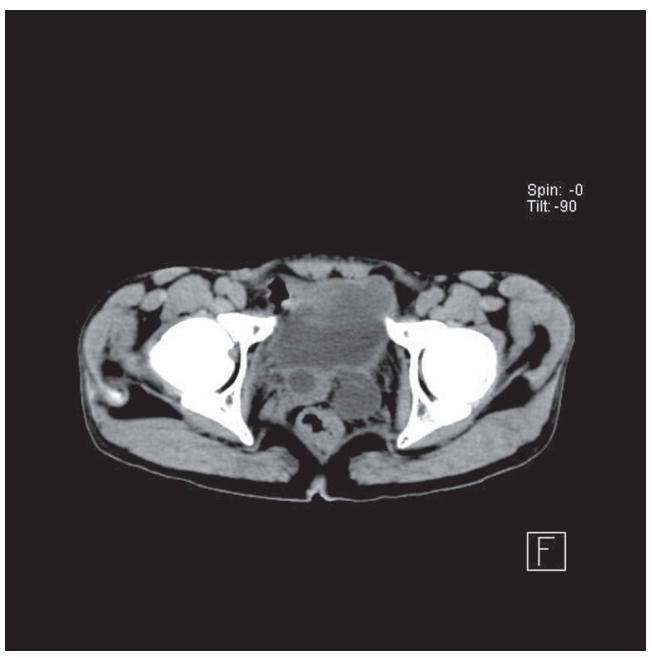

Figure 2. Dilated ureters posterior to bladder neck.

\section{Case Report}

A 35-year-old male, a known case of hypertension presented with pain in left lumbar region for 12 years, which exaggerated 2 months ago. Patient gives history of dull pain in the epigastric region and fullness of the abdomen. There is no past history of febrile urinary tract infections.

Patient works as a laborer, married and has three children. He was a chronic alcoholic and gave history of analgesic abuse. There is no similar family history. His general and local examination was unremarkable with normal external genitalia. Digital rectal examination showed normal sized prostate. His renal functions were deranged with blood urea of $180 \mathrm{mg} \%$ and serum creatinine of $6.0 \mathrm{mg} \%$. Urine analysis showed sterile pyuria with $8-10 \mathrm{RBC} / \mathrm{HPF}$.

Ultrasonograph of abdomen revealed bilateral hydroure-

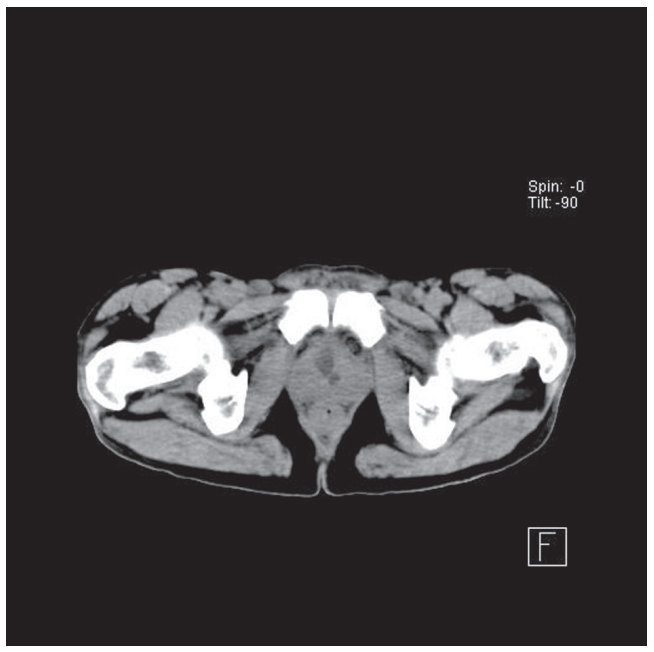

Figure 3. Ureters opening into proximal prostatic urethra.

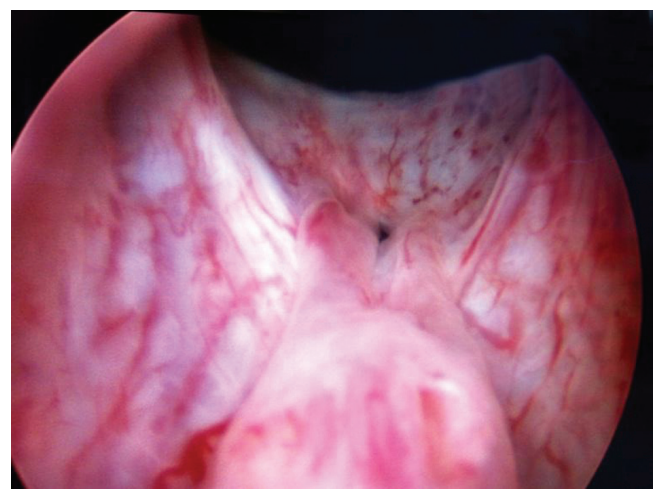

Figure 4. Left patulous ureteric opening with effaced right ureterocele.

teronephrosis with hardly any parenchyma on left side with ectopic opening of ureters in the proximal prostatic urethra. TRUS examination showed non-visualized left seminal vesicle in addition to the above findings. Non-contrast CT (Fig. 1-3) and MRI showed the anatomical details but no ureterocele was reported. No vesicoureteric reflux was seen in the voiding cystourethrogram film.

Cystourethroscopy revealed bilateral ectopic ureters opening into prostatic urethra just proximal to the verumontanum. Left ureteric opening was patulous (Fig. 4). Right ureterocele was visible in the empty bladder with a dimple of stenosed opening and this ureterocele was overlapping and obstructing the left ureteric opening (Fig. 5). Right ureterocele got effaced on distending the bladder and bladder neck was wide open. Trigone was absent. Urinary bladder was of normal capacity, congested and mildly trabeculated. Ureteroscope when passed into left patulous ureteric opening led to dilated tortuous left ureter. Right ureteric opening could not be identified.

Transurethral incision of the right ureterocele was done by using a resectoscope with Collins hot knife (Fig. 6). A longitudinal incision was given extending from the bladder neck to the stenosed opening of right ureterocele to

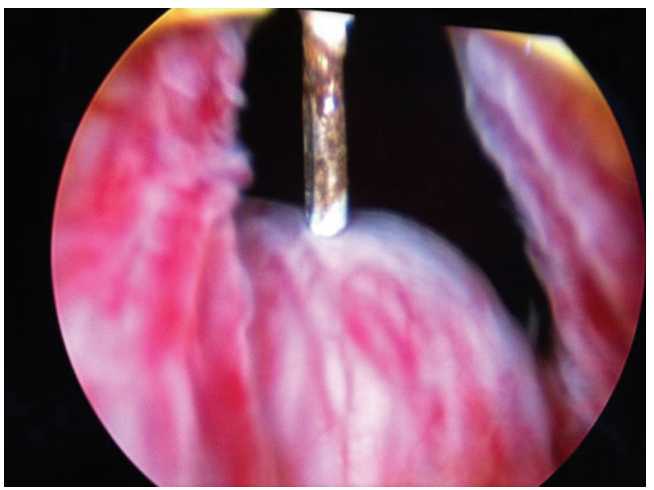

Figure 5. Right sphincterostenotic ureterocele visible in empty bladder. 


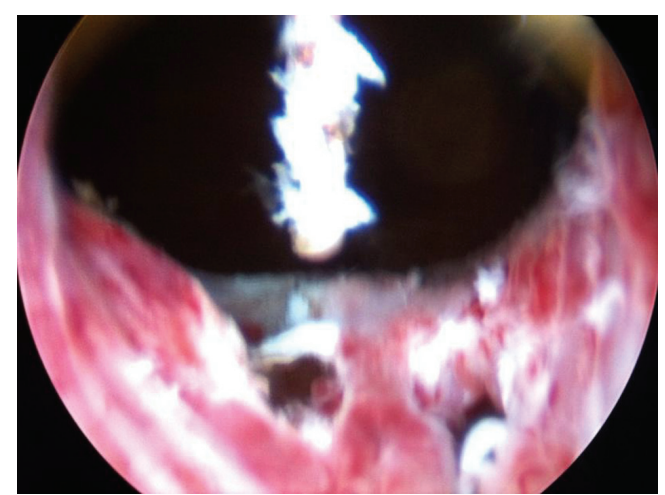

Figure 6. Right ureterocele incised with Collins hot knife.

improve drainage of the right solitary functioning kidney. Right double J stent was placed. Subsequently renal functions improved and his creatinine came down to $1.6 \mathrm{mg} \%$. $\mathrm{He}$ is planned for left nephroureterectomy and if necessary right ureteric re-implantation as a secondary major surgery in the follow-up period.

\section{Discussion}

BSSEUs are fortunately rare because they present a complex therapeutic problem [1]. In males the ureters usually drain into the prostatic urethra. Other sites include seminal vesicles, vas deferens, ejaculatory duct and epididymis. The ectopic ureters open above the external urinary sphincter in males so they do not have urinary incontinence but typically present with hydroureteronephrosis and symptomatic urinary tract infections. Associated anomalies are common in BSSEU in the form of agenesis or dysplasia of the kidney. Our patient has agenesis of the left seminal vesicle associated with BSSEU. Bladder neck and trigone are maldeveloped in $75 \%$ of BSSEU [1], but spontaneously increased bladder capacity may occur with time $[2,4]$ and patients can achieve normal bladder function [5]. Both these findings are corroborated in this case as this patient had normal bladder function and capacity along with normal voiding and was fully continent.

The specific mechanisms responsible for the development of ectopic ureter and ureterocele are probably abnormal ureterotrigonal development and failure of rupture or degeneration of Chwalle membrane. Obstruction leading to hydroureteronephrosis is due to intrinsic muscular defect in the ureteral wall and also due to close approximation of the ectopic ureteral orifice to the internal urethral sphincter. In this case in spite of the sphincterostenotic ureterocele, the deterioration of the upper tracts and renal functions was more on the contralateral side. This may be due to the ureterocele causing mechanical obstruction to the otherwise patulous contralateral ureteric orifice and thus leading to the non-functioning hydronephrotic kidney.

In this case the ectopic ureterocele was missed on ultrasonography, CT and MRI abdomen but was obvious on cystourethroscopy in the empty bladder and got effaced on distending the bladder, so concurrent endoscopic evaluation is important for final diagnosis and operative intervention. The ureterocele was incised longitudinally over the stenosed orifice with Collins hot knife and double J stent was placed to improve renal functions.

\section{References}

1. Kesavan P, Ramakrishnan MS, Fowler R. Ectopia in unduplicated ureters in children. Br J Urol. 1977;49(6):481493.

2. Williams DI, Lightwood RG. Bilateral single ectopic ureters. Br J Urol. 1972;44(2):267-273.

3. Redman JF, Lightfoot ML, Reddy PP. Bilateral single ureteral ectopia in a boy. Urology. 2002;60(3):514.

4. Williams DI, Royle M. Ectopic ureter in the male child. Br J Urol. 1969;41(4):421-427.

5. Podesta E, Scarsi PL, Di Rovasenda E, Ferretti S, Magillo P, Dodero P. Vesical continence in bilateral ectopic single ureters. J Urol. 2001;165(6 Pt 2):2363-2365. 